\title{
Usual food intakes of 2- and 3-year old U.S. children are not consistent with dietary guidelines
}

Mary Kay Fox ${ }^{1^{*}} \mathbb{D}$, Elizabeth Gearan ${ }^{1}$, Judith Cannon ${ }^{2}$, Ronette Briefel ${ }^{3}$, Denise M. Deming ${ }^{4}$, Alison L. Eldridge ${ }^{5}$ and Kathleen C. Reidy ${ }^{4}$

\begin{abstract}
Background: The primary purpose of this paper is to assess how well food consumption patterns of young children in the U.S. conform to the 2015 Dietary Guidelines for Americans. A secondary purpose is to gain insight into food choices that contribute to over- or under-consumption of key food groups and dietary constituents.

Methods: The analysis used data from the Feeding Infants and Toddlers Study 2008 (FITS 2008), and a national random sample of 1323 2- and 3-year old U.S. children. Children's usual food intakes were estimated using the National Cancer Institute method and proportions of children whose usual diets did not include recommended amounts of food groups were assessed, as well as the proportions that consumed excess calories from solid fat and added sugars. Leading sources of vegetables, grains, oils, solid fat and added sugars were also examined.

Results: The prevalence of usual food group intakes that did not meet recommendations was highest for vegetables (91\%), whole grains (94\%), and oils (>99\%). In addition, virtually all children (>99\%) had usual intakes of calories from solid fat and added sugars that exceeded the maximum allowance. The mean intake of calories from solid fat and added sugars was almost three times the maximum allowance.

Conclusions: Given that children's food preferences and habits develop early in life, educating primary caregivers about recommended feeding patterns and how to promote them is critical. Infants and young children will readily accept sweet and salty foods, but the wider variety of foods associated with healthy eating patterns may only be accepted if children have repeated experience with them. There is evidence that some caregivers may overestimate the quality of their children's diets, so specific, practical, and actionable guidance is needed. This advice should include education about children's normal resistance to new foods, strategies for promoting acceptance and not using food to manage behavior. Given that one-third of children under the age of five attend regular child care outside the home, child care centers and family day care homes also have an important role to play in developing healthy food habits and preferences among young children.
\end{abstract}

Keywords: Diet, Food consumption, Food groups, Preschool, Children, Dietary Guidelines

\footnotetext{
* Correspondence: mfox@mathematica-mpr.com

${ }^{1}$ Mathematica Policy Research, 955 Massachusetts Avenue, Cambridge, MA

02138, USA

Full list of author information is available at the end of the article
} International License (http://creativecommons.org/licenses/by/4.0/), which permits unrestricted use, distribution, and reproduction in any medium, provided you give appropriate credit to the original author(s) and the source, provide a link to the Creative Commons license, and indicate if changes were made. The Creative Commons Public Domain Dedication waiver (http://creativecommons.org/publicdomain/zero/1.0/) applies to the data made available in this article, unless otherwise stated. 


\section{Background}

Data from national surveys have shown that preschool children (under 5 years of age) in the U.S. consume diets that provide recommended amounts of essential vitamins and minerals [1-4]. At the same time, evidence shows that these "well-nourished" preschool children consume excessive amounts of saturated fat and sodium and low levels of dietary fiber [1-4]. Moreover, while the prevalence of obesity in this age group has leveled off since 2003 [5-8], it is still double what it was 30 years ago [9]. These paradoxical findings point to the importance of food choices and dietary patterns in shaping overall diet quality.

The Dietary Guidelines for Americans, which are jointly issued by the U.S. Departments of Agriculture (USDA) and Health and Human Services are updated every 5 years and provide evidence-based guidance on dietary patterns that promote health, reduce the risk of chronic disease, and reduce the prevalence of overweight and obesity [10]. The Dietary Guidelines are further translated into Healthy U.S.-Style Eating Patterns, which provide guidance on the specific types and amounts of food to consume based on age, sex, and physical activity level [10]. Research has shown that the diets of most Americans, including children, are not consistent with these recommended eating patterns [11-13]. However, few studies have examined dietary patterns of children 2-3 years of age. This gap in knowledge about the diets of very young children is critically important because evidence shows that eating patterns and food preferences are established early in life [14-17]. In addition, as nutrition experts are working to extend the Dietary Guidelines to include guidance for children from birth to 24 months [18], it is important to understand how consumption patterns of our youngest children compare to current recommendations.

The primary purpose of this study is to assess the extent to which the food consumption patterns of 2-3 year old children in the U.S., collectively, as well as separately by year of age, conform to the 2015 Dietary Guidelines for Americans [10]. A secondary purpose is to gain insight into the food choices that contribute to over- or under-consumption of key food groups and dietary constituents. The analysis used data from the Feeding and Infants and Toddlers Study, 2008 (FITS), which has made major contributions to our understanding of the food and nutrient intakes of children from birth through 24 months $[1,4,18-23]$.

\section{Methods}

FITS 2008 is a cross-sectional, descriptive survey of a national random sample of U.S. children from birth up to 4 years ( $\leq 47.9$ months) of age. The sample frame, recruitment and data collection procedures, response rates, and sample characteristics are described in detail elsewhere [24]. In brief, two commercial sample frames were used to identify U.S. households with a child under the age of 4 years. Data were weighted to reflect vital statistics birth data for 2008. All survey instruments and procedures [25] were approved by Mathematica's independent institutional review board at the time of the study (Public/Private Ventures in Philadelphia, Pennsylvania). All participants received written information about the study, understood that participation was voluntary, and were assured of the confidentiality of the data.

Data were collected by telephone between June 2008 and January 2009 and included two main components: (1) a recruitment interview that collected data on household and child characteristics, feeding practices, child activity and WIC participation, and (2) a diet interview (conducted at a later date) that included a 24-h dietary recall and a brief set of questions about breastfeeding, introduction of foods, and caregivers' perceptions about the target child's diet and weight status. A representative subsample of caregivers (17\%) completed a second 24-h dietary recall 7 to 10 days after the first dietary recall. Prior to the first recall, respondents were mailed an introductory letter, tools to use in estimating portion sizes (food model booklet, ruler, liquid measuring cup), and guidelines for gathering information about foods the child consumed while in child care. Certified dietary interviewers at the University of Minnesota's Nutrition Coordinating Center conducted the 24-h recalls, using the FITS 2008 protocol and the Nutrition Data System for Research (NDS-R software version 2008, University of Minnesota, Minneapolis, Minnesota). Respondents received an incentive of $\$ 20$; those who completed the second 24-h recall received an additional \$10. Dietary recalls were collected for both weekend days (Saturday or Sunday) and weekdays (Monday through Friday). In the full FITS 2008 sample, approximately $26 \%$ of the recalls reflected weekend days and $74 \%$ reflected weekdays. Additional information about data collection methods is reported elsewhere [26]. Interviews were conducted in English or Spanish.

The analyses presented in this paper focus on children 2 - and 3-years of age (24.0 to 47.9 months). A total of 138 children in these age groups were excluded from the analysis because they were missing data on household income, an important covariate in the models used to estimate usual food intake distributions. Data are presented for 2- and 3-year olds overall $(n=1323)$ and by year of age (2-year olds $n=666$ and 3 -year olds $n=657$ ).

\section{Assessment of food patterns}

To compare children's food intakes to recommended food patterns, foods reported in the 24-h recalls were converted into amounts of food groups using USDA's MyPyramid Equivalents Database (MPED), version 2.0 
[26]. In the MPED, single-ingredient foods that are in their lowest-fat, lowest-sugar form, such as a fresh peach, skim milk, or fresh carrots, are assigned to a single major food group. Food mixtures that have ingredients from more than one food group are disaggregated and individual ingredients are assigned to appropriate food groups. For example, a cheese pizza is separated into its main ingredients of crust, cheese, and tomato sauce, and assigned values for the relevant food groups-grains, dairy, and vegetables. Foods that have added fat and/or sugar, such as peaches canned in heavy syrup or whole milk, have MPED entries for both the relevant food group(s) and for grams of solid fat and/or added sugars.

The MPED was the optimal source of data on food group content at the time these analyses were conducted. Adjustments were made to variables in the MPED to reflect the USDA's Food Pattern categorization of soy beverages under the dairy group and red vegetables as part of the orange vegetables group [10]. Some food groups were collapsed when reporting consumption when intakes of individual items were low (e.g., total protein foods were reported rather than sub-groups of seafood, meats, nuts; total vegetables, orange/red, starchy and other vegetables were reported separately, but green vegetables and legumes were only included in total vegetables because so few children reported consuming them). Additional adjustments were made for breast milk and infant formula, both of which were assigned to the dairy group, because the MPED does not include these foods. Calories from solid fat and added sugar were reported as discretionary calories.

\section{Statistical analyses}

Usual food intake distributions were estimated using SAS macros developed by the National Cancer Institute [27]. A one-part linear model was used to estimate usual intake distributions of foods that were consumed daily by almost all individuals in the sample (total fruit, total vegetables, total grains, dairy, protein foods, oils), and a two-part linear model was used to estimate usual intake distributions for foods that were consumed more episodically (whole fruit, vegetable subgroups, and whole grains). The twopart model first estimates the probability of consumption using logistic regression with a person-specific random effect and then specifies the consumption-day amount using linear regression on a transformed scale [11]. All models included covariates to account for sequence effect (in case the first 24-h recall was different from the second [11], day of the week (weekday/weekend day), income (household income $\leq 185 \%$ or $>185 \%$ of the federal poverty level), gender, and race/ethnicity (non-Hispanic white, non-Hispanic black, Hispanic, all others). All analyses used FITS 2008 sample weights that were calculated to account for nonresponse and to reflect the U.S. population from birth to 4 years of age, based on child's age in months at the time of recruitment into the study and mother's race [24].

Usual food intakes were compared to recommended amounts in the 1000 cal USDA Healthy U.S.-Style Eating Pattern and the percentages of children, overall and by year of age, that did not meet the various recommendations were estimated. The $1000 \mathrm{cal}$ food pattern is recommended for all 2-year-olds and for sedentary 3-year-olds [10]. Although energy requirements for moderately active 3-year-olds are higher (1200 cal for girls and $1400 \mathrm{cal}$ for boys), the 1000 cal benchmark was chosen because current Dietary Reference Intakes for energy (based on estimated Total Energy Expenditure) have been found to overestimate energy requirements because of erroneous classification of children into higher levels of physical activity [28]. Comparison of usual food group intakes to this lowest-calorie reference provides a lower bound estimate of the prevalence of usual food intakes that are not consistent with Dietary Guidelines recommendations. As shown in Table 1, recommended intakes for most food groups increase as calorie levels increase and the allowance for discretionary calories decreases. Thus, if the higher-calorie food patterns were used in the analysis, the percentages of children not meeting recommendations would be even higher.

To gain insight into the food choices that contribute to problematic patterns observed in children's diets, the leading contributors of total vegetables, total grains, whole grains, oils, and calories from solid fat and added sugars were identified. For this analysis, a food classification database created for FITS 2002 and updated for FITS 2008 was used $[19,20]$. This food classification system grouped all foods reported in the 24-h recalls into 84 mutually exclusive food groups (hereafter referred to as food sources groups) based on similarities in nutrient content and food use [20]. The contribution of each of the food sources groups to children's intakes of USDA's Healthy U.S.-Style Eating Pattern food groups was estimated using population proportions $[21,29,30]$. This was done by summing the weighted amount of a given food group (for example, total vegetables, total grains, or whole grains) provided by a given food sources group for all children in the sample and dividing by the total weighted amount of that food group consumed by all children from all foods. Comparable tabulations were completed for oils and discretionary calories, defined here as calories from solid fat and added sugars. In interpreting results of this analysis, it is important to note that the relative contribution of a particular food sources group to intakes of specific food groups, oils, or discretionary calories from solid fat and added sugars is determined by both the composition of the foods included in the group and the frequency with which those foods were consumed [29]. 
Table 1 Healthy U.S.-Style Eating Pattern for calorie levels ranging from 1000 to 1400 per day

\begin{tabular}{|c|c|c|c|}
\hline Food Group & 1000 Calories & 1200 Calories & 1400 Calories \\
\hline Vegetables $^{a}$ & 1 cup & 1.5 cup & 1.5 cup \\
\hline Dark green vegetables ${ }^{a, b}$ & 0.07 cup & 0.14 cup & 0.14 cup \\
\hline Red and orange vegetables ${ }^{a, b}$ & 0.36 cup & 0.43 cup & 0.43 cup \\
\hline Legumes $^{a, b}$ & 0.07 cup & 0.07 cup & 0.07 cup \\
\hline Starchy vegetables ${ }^{a, b}$ & 0.29 cup & 0.5 cup & 0.5 cup \\
\hline Other vegetables ${ }^{\mathrm{a}, \mathrm{b}}$ & 0.21 cup & 0.36 cup & 0.36 cup \\
\hline Fruits $^{a}$ & 1 cup & 1 cup & 1.5 cup \\
\hline Grains $^{c}$ & $3 \mathrm{oz}$. & $4 \mathrm{oz}$. & $5 \mathrm{oz}$. \\
\hline Whole grains ${ }^{c}$ & $1.5 \mathrm{oz}$ & $2 \mathrm{oz}$ & $2.5 \mathrm{oz}$ \\
\hline Refined grains ${ }^{c}$ & $1.5 \mathrm{oz}$. & $2 \mathrm{oz}$ & $2.5 \mathrm{oz}$ \\
\hline Dairy $^{d}$ & 2 cups & 2.5 cups & 2.5 cups \\
\hline Protein foods ${ }^{e}$ & $2 \mathrm{oz}$. & 3 oz. & $4 \mathrm{oz}$. \\
\hline Seafood ${ }^{e, f}$ & $0.43 \mathrm{oz}$ & $0.57 \mathrm{oz}$ & $0.86 \mathrm{oz}$ \\
\hline Meats, poultry, eggs ${ }^{\mathrm{e}, f}$ & $1.43 \mathrm{oz}$. & $2 \mathrm{oz}$. & $2.71 \mathrm{oz}$. \\
\hline Nuts, seeds, soy products ${ }^{\mathrm{e}, \mathrm{f}}$ & $0.29 \mathrm{oz}$ & $0.29 \mathrm{oz}$ & $0.43 \mathrm{oz}$ \\
\hline Oils & $15 \mathrm{~g}$ & $17 \mathrm{~g}$ & $17 \mathrm{~g}$ \\
\hline Limit on Discretionary Calories $^{9}$ & $150 \mathrm{kcal}$ & $100 \mathrm{kcal}$ & 110 kcal \\
\hline
\end{tabular}

Source: http://health.gov/dietaryguidelines/2015/guidelines/ [10], Table A3-1

Note: The 1000 cal food pattern was used as the reference pattern in the analysis

a Recommended intakes of fruits and vegetables are expressed in cup equivalents. A cup equivalent of fruit or vegetable is equal to 1 cup of raw or cooked fruit or vegetable, 1 cup of juice, 2 cups of leafy salad greens or $1 / 2$ cup dried fruit or vegetable. Recommendations state that at least half of fruit servings should come from whole fruits

${ }^{\mathrm{b}}$ Recommended intakes for vegetable subgroups are expressed as cup equivalents per week in the Dietary Guidelines. Weekly recommendations were converted to daily recommendations for this analysis by dividing by 7

${ }^{C}$ Recommended intakes of grains and whole grains are expressed in ounce equivalents. An ounce equivalent of grains is equal to $1 / 2$ cup of cooked rice, pasta, or cereal, a 1-oz slice of bread, or $1 \mathrm{oz}$ of ready-to-eat cereal (about 1 cup of flaked cereal)

${ }^{d}$ Recommended intake of dairy is expressed in cup equivalents. A cup equivalent of dairy is equal to 1 cup of milk, yogurt or fortified soy milk, 1.5 oz. of natural cheese, or 2 oz. of processed cheese

${ }^{e}$ Recommended intake of protein foods is expressed in ounce equivalents. An ounce equivalent is equal to $1 \mathrm{oz}$ of lean meat, poultry or seafood, 1 egg, $1 / 4$ cup cooked beans or tofu, 1 tablespoon peanut butter, or $1 / 2$ ounce nuts or seeds

${ }^{\mathrm{f}}$ Recommended intakes for protein subgroups are expressed as ounce equivalents per week in the Dietary Guidelines. Weekly recommendations were converted to daily recommendations for this analysis by dividing by 7

${ }^{9}$ Discretionary calories may include calories from added sugars, added refined starches, solid fats or additional amounts from other food groups

\section{Results}

The percentage of children ages 2- and 3-years of age with usual intakes of USDA's Healthy U.S.-Style Eating Pattern food groups below recommended levels ranged from a low of $16 \%$ for total grains to a high of essentially $100 \%$ for oils (Table 2). The prevalence of usual intakes that did not meet minimum recommendations was greatest for oils (nearly 100\%), whole grains (94\%) and total vegetables (91\%). The percentage of children not meeting recommendations was high for sub-groups of vegetables as well (including contributions from mixed dishes) with 99\% below recommendations for orange and red vegetables, $85 \%$ below recommendations for other vegetables, and $76 \%$ below recommendations for starchy vegetables. Few children consumed dark green vegetables or legumes so these were not reported separately in Table 2 (sample sizes were too small to provide reliable estimates of intake). Virtually all children had usual intakes of discretionary calories from solid fat and added sugars that exceeded the maximum allowance. The mean usual intake of calories from solid fat and added sugars was $409 \mathrm{cal}$-more than 2.5 times the recommended maximum of 150 discretionary calories. Fewer children fell below recommendations for protein intake (32\%) and for dairy (48\%).

For several food groups, there were notable variations in findings for 2- and 3-year olds. For total fruit, whole fruit, and whole grains, the prevalence of usual intakes that did not meet recommendations was higher for 3-year-olds than for 2-year-olds. The difference between the two age groups ranged from 8 to 14 percentage points and was greatest for whole grains (98\% versus $84 \%$, respectively). For other vegetables, total grains, and protein foods, the pattern was reversed, with higher percentages of 2-yearolds than 3-year-olds having usual intakes that did not meet recommendations. The difference between the two age groups ranged from 9 to 20 percentage points and was greatest for protein foods (40\% versus $20 \%$ ). 
Table 2 Mean usual intakes by Healthy U.S.-Style Eating Pattern food groups and percentage of 2- and 3-year olds below or above recommended amounts

\begin{tabular}{|c|c|c|c|c|c|c|c|}
\hline \multirow[b]{2}{*}{ Food Group } & \multirow[b]{2}{*}{$\begin{array}{l}\text { Recommended daily } \\
\text { intake amount }^{a}\end{array}$} & \multicolumn{2}{|c|}{ 2- and 3-year olds } & \multicolumn{2}{|l|}{ 2-year olds } & \multicolumn{2}{|l|}{ 3-year olds } \\
\hline & & $\begin{array}{l}\text { Mean usual } \\
\text { intake } \\
\text { Mean (SE) }\end{array}$ & $\%$ Below & $\begin{array}{l}\text { Mean usual } \\
\text { intake } \\
\text { Mean (SE) }\end{array}$ & $\%$ Below & $\begin{array}{l}\text { Mean usual } \\
\text { intake } \\
\text { Mean (SE) }\end{array}$ & $\%$ Below \\
\hline Vegetables $^{b}$ & 1 cup & $0.64(0.01)$ & 91.4 & $0.64(0.01)$ & 92.1 & $0.63(0.01)$ & 91.7 \\
\hline Red and orange vegetables ${ }^{c}$ & 0.36 cup & $0.22(0.00)$ & 99.3 & $0.21(0.00)$ & 94.2 & $0.22(0.00)$ & 93.0 \\
\hline Starchy vegetables ${ }^{c}$ & 0.29 cup & $0.22(0.00)$ & 75.9 & $0.24(0.00)$ & 77.1 & $0.21(0.01)$ & 77.3 \\
\hline Other vegetables ${ }^{c}$ & 0.21 cup & $0.14(0.00)$ & 84.5 & $0.14(0.00)$ & 88.4 & $0.15(0.00)$ & 79.8 \\
\hline Fruits & 1 cup & $1.49(0.02)$ & 32.1 & $1.52(0.03)$ & 28.2 & $1.45(0.04)$ & 36.0 \\
\hline Whole fruit $^{d}$ & 0.5 cup & $0.82(0.01)$ & 27.4 & $0.87(0.02)$ & 23.5 & $0.76(0.02)$ & 33.9 \\
\hline Grains & $3 \mathrm{oz}$ & $4.16(0.03)$ & 16.3 & $3.96(0.05)$ & 23.1 & $4.37(0.04)$ & 11.1 \\
\hline Whole grains & $1.5 \mathrm{oz}$ & $0.85(0.01)$ & 93.6 & $0.91(0.03)$ & 84.4 & $0.78(0.01)$ & 98.3 \\
\hline Dairy & 2 cups & $2.21(0.03)$ & 47.7 & $2.18(0.05)$ & 49.9 & $2.23(0.04)$ & 45.6 \\
\hline Protein foods ${ }^{\mathrm{e}}$ & $2 \mathrm{oz}$ & $2.59(0.03)$ & 31.9 & $2.49(0.05)$ & 39.5 & $2.69(0.03)$ & 19.5 \\
\hline \multirow[t]{2}{*}{ Oils $^{f}$} & $15 \mathrm{~g}$ & $7.18(0.07)$ & $\geq 99$ & $6.47(0.04)$ & $\geq 99$ & $7.90(0.14)$ & $\geq 99$ \\
\hline & & & $\%$ Above & & $\%$ Above & & $\%$ Above \\
\hline $\begin{array}{l}\text { Discretionary Calories from } \\
\text { Solid Fats + Added Sugarf,g }\end{array}$ & 150 calories & 409 (3.6) & $\geq 99$ & $385(4.5)$ & $\geq 99$ & $434(1.2)$ & $\geq 99$ \\
\hline
\end{tabular}

SE standard error

${ }^{\text {a }}$ Recommended amounts are based on a 1000 calorie USDA Healthy U.S.-Style Eating Pattern. For all items other than discretionary calories (defined here as calories from solid fat and added sugars), recommended amounts are minimums. The recommendation for discretionary calories is the maximum allowance ${ }^{b}$ We were unable to reliably estimate usual intake distributions for dark green vegetables and legumes because so few children consumed these foods. Dark green vegetables and legumes are, however, included in the total vegetables category

${ }^{c}$ Recommended amounts for vegetable subgroups reflect weekly recommendations divided by 7

${ }^{d}$ Whole fruit is included here to assess the recommendation that at least half of fruit servings come from whole fruits

eLegumes were first allocated the meat and beans group; any amount remaining after the protein foods recommendation was met were counted toward the legumes and total vegetable groups

fPoint estimates are considered to be imprecise because of very common effect; all were calculated between 99 and $100 \%$ and are shown here as $>99$

${ }^{9}$ Calories from solid fat and added sugars were computed as follows: (solid fat $(\mathrm{g}) * 9$ calories) + (added sugars (tsp) * 16 calories)

\section{Sources of vegetables}

About two-thirds of the vegetables consumed by children came from discrete servings of vegetables and almost onequarter came from mixed dishes that included vegetables (Additional file 1). The remaining $10 \%$ of vegetables was contributed by an array of different foods/food groups, most of which made only marginal contributions. Chips and other salty snacks (mostly potato chips) and condiments (mostly ketchup) were exceptions, contributing about 5 and $3 \%$ of vegetables, respectively. White potatoes accounted for the largest share of children's vegetable intakes (17\%). Other specific foods/food groups that were leading sources of vegetables in children's diets (among the top 10) include pasta-based mixed dishes (spaghetti, ravioli, and lasagna), which primarily contributed tomato sauce $(9 \%)$; other vegetables $(8 \%)$; carrots $(7 \%)$; green beans $(7 \%)$; corn $(5 \%)$; broccoli $(5 \%)$; discreet servings of tomatoes and tomato sauce (not part of a mixed dish) (5\%); chips and other salty snacks (5\%); and pizza (5\%).

\section{Sources of total grains}

More than half (57\%) of the grains consumed by 2- and 3 -year-olds came from grains and grain products, $23 \%$ came from mixed dishes that included grains, $17 \%$ came from desserts, candy, chips, and other snack foods, and 3\% came from (breaded) meat, fish, and poultry products (Additional file 1). Breads, rolls, biscuits, bagels, and tortillas were, by far, the leading contributors to children's total grain intakes, including those reported and coded separately in the 24-h recalls (20\%) and those included in various types of sandwiches and tortillabased mixed dishes (8\%). Other specific foods/food groups included among the top 10 contributors to children's total grain intakes included breakfast cereals (ready-to-eat and hot) (11\%); crackers, pretzels, and rice cakes (10\%); cookies (6\%); cakes, pies, and other baked goods (6\%); pancakes, waffles, and French toast (5\%); macaroni and cheese (4\%), pizza (4\%), rice $(4 \%)$, and spaghetti, ravioli, and lasagna (4\%).

\section{Sources of whole grains}

The vast majority (90\%) of whole grains consumed by children came from grains and grain products (Additional file 1). Desserts, candy, snack chips, and other snack foods accounted for $8 \%$ of whole grains, and the remaining $2 \%$ was contributed by milk and mixed dishes. Relatively few 
foods/food groups contributed whole grains. Almost twothirds of whole grains consumed by 2- and 3-year-old children came from ready-to-eat and hot cereals (39\%) and breads, rolls, biscuits, bagels, and tortillas (28\%).

\section{Sources of oils}

The oils consumed by 2- and 3-year old children came from a wide variety of food sources (Additional file 1). Almost $40 \%$ of oils was contributed by protein foods, and another $24 \%$ was contributed by desserts, candy, chips, and other snack foods. Mixed dishes, added fats (fats reported and coded separately in the 24-h recalls), and grains and grain products each contributed about $10 \%$ of oils (11, 9 and $9 \%$, respectively). The three leading contributors to children's intake of oils, which accounted for $55 \%$ of intake, were chicken and turkey (mostly breaded, pre-processed items) (22\%), chips and other salty snacks (17\%), and peanut butter, nuts, and seeds (16\%). Other foods/food groups included among the top 10 contributors include salad dressings and mayonnaise (7\%); peanut butter sandwiches $(5 \%)$; white potatoes (mainly French fries and similar potato products) (4\%); candy (3\%); bread, rolls, biscuits, bagels, and tortillas (3\%); cakes, pies, and other baked goods (2\%), and butter, oil, margarine, and other fats (2\%).

\section{Sources of discretionary calories from solid fat and added sugars}

Children obtained discretionary calories from a variety of foods (Additional file 1). The leading contributors were milk and milk products (28\%) and desserts, candy, chips, and other snack foods (18\%). Together these two groups of foods contributed almost half (46\%) of all calories from solid fat and added sugars. Mixed dishes, grains and grain products, sweetened beverages, and protein foods each contributed roughly $10 \%$ of calories from solid fat and added sugars (range $=9$ to 13\%). Specific foods/food groups that were leading sources of these calories included (flavored) milk (18\%); sweetened beverages (9\%), the majority of which were fruit-flavored drinks, but also included carbonated sodas, energy/sport drinks, and sweetened tea and coffee; cheese (6\%); cookies $(5 \%)$; cakes, pies, and other baked goods (5\%). Together, these five food groups accounted for $43 \%$ of calories from solid fat and added sugars overall. Other leading contributors of these calories for 2- and 3-yearolds included hot dogs, cold cuts, sausages and bacon (5\%); yogurt (4\%); crackers, pretzels and rice cakes (mainly crackers) (4\%); ready-to-eat and hot cereals (4\%); and pizza (3\%). In combination, these 10 foods accounted for $62 \%$ of all calories from solid fat and added sugars.

\section{Discussion}

This analysis of data from FITS 2008 shows that eating patterns that are inconsistent with the Dietary Guidelines-patterns that are well documented among adults and older children in the U.S.-are already apparent among 2- and 3-year old children. Almost all children in this age range consumed diets that were low in vegetables, oils, and whole grains, and high in discretionary calories from solid fat and added sugars, relative to 2015 Dietary Guidelines recommendations. In addition, appreciable percentages of children consumed less dairy (milk, cheese, and yogurt), fruit, and lean protein foods than recommended. These findings are consistent with results from the U.S. National Health and Nutrition Examination Survey (NHANES) 2001-2004, where the majority of people across all ages consumed fewer vegetables, whole grains, fruits, dairy and oils relative to recommendations along with pervasive overconsumption of solid fats and added sugars [11].

One possible explanation is that children are not exposed enough to healthy choices during infancy. Research has shown that it is important to expose children to healthy foods and flavors early in life as taste preferences are developing [31]. Food neophobia, or the dislike of a new or novel food, is minimal in infancy and is thought to peak between 2 and 6 years of age [32]. A longitudinal analysis of food preferences among young children found that newly tasted foods were more likely to be accepted before age 4 than between ages 4 and 8 [17]. Aversion to new foods may have negative effects on dietary variety. Two-year-old children with high levels of neophobia had lower dietary quality, less variety in fruit and vegetable intakes, and a higher percentage of total energy intake from foods that were high in calories and low in nutrients than children with lower levels of neophobia [33].

Human beings are born with innate positive responses to sweet and salty tastes and negative responses to bitter and sour tastes [34]. As Birch and Doub point out, infants and young children will readily accept the inexpensive, energy-dense, sweet, and salty foods that permeate the current U.S. food environment [31]. This makes it easy to establish unhealthy dietary patterns and more difficult to establish healthy patterns that include a variety of foods. Acceptance of initially rejected foods can be increased by repeated exposure, particularly when paired with familiar or preferred foods $[35,36]$ and by adult modeling of the desired behavior $[37,38]$.

Findings about the foods that contributed to intakes of vegetables, grains, oils, and calories from solid fat and added sugars offer insights about strategies for improving children's diets. For example, the finding that more than $90 \%$ of all children failed to consume the recommended 
amount of total vegetables, even when contributions from foods such as potato chips and ketchup were considered, signals a critical need to focus on increasing children's vegetable consumption. The fact that consumption of dark green vegetables was so infrequent that it was not possible to reliably estimate usual intakes highlights the need to increase children's early exposure to these nutrient-dense vegetables. These results showed that white potatoes accounted for two to three times more of total vegetable intake than any of the other leading contributors indicating a need to increase the variety of vegetables being fed to young children. The fact that the majority of white potatoes consumed were French fries or similar fried potato products, as shown in a previous analysis of 2008 FITS data [20], further underscores this concern. Finally, it is worth noting that almost one-third of the vegetables children consumed came from mixed dishes and other foods, including extras such as potato chips and ketchup. Branum and Rossen found that the relative contribution of mixed dishes to total vegetable intake increased with age, from $39 \%$ among $2-5$ year olds to $46 \%$ among 16-18 year olds [39]. While greater use of vegetables as part of popular mixed dishes may be a strategy to increase total vegetable consumption, it may also be important to encourage children's acceptance and consumption of vegetables as discrete food items.

The contrast between the lists of foods that contribute to total grain intake and intake of whole grains illustrates why children's whole grain intakes are so low. The whole grains that children do consume are concentrated in very few foods. Thus, few of the grain products that children consume, whether as discrete servings or in mixed dishes, include whole grains. For example, while the data show that breads and rolls contribute more than one-quarter of whole grain intake, they also show that few of the sandwiches children consume are made with whole grain breads. Sandwiches contributed $8 \%$ of children's total grain intakes but accounted for less than $1 \%$ of whole grains. To increase whole grain intakes to levels that are consistent with the Dietary Guidelines without increasing energy intakes, whole grain options must be substituted for the non-whole grain options currently consumed to the fullest extent possible. In addition to offering whole grain cereals, breads, rolls, and tortillas, caregivers should be encouraged to choose and prepare foods that include other sources of whole grains, such as whole grain crackers, brown rice and whole grain pasta (served alone or in mixed dishes).

Children's low intake of oils is consistent with patterns observed in the U.S. population overall [11] and reflects the fact that Americans consume limited amounts of the foods that the 2015 Dietary Guidelines recommends as the main source of oils-fish, nuts, and vegetable oils that are high in polyunsaturated and monounsaturated fatty acids. Intake of nuts in this age group could also be limited because of the potential choking hazard [40]. Other sources of healthy fats and oils that are developmentally appropriate for this age group include fish, avocados, salad dressings and a variety of foods formulated with healthy oils including canola. Serving small amounts of dips with vegetables (cooked, if necessary to make them developmentally appropriate), which has been shown to increase consumption of vegetables in young children [41], could also lead to increased consumption of oils.

Excessive consumption of discretionary calories from solid fat and added sugars is a major concern. Children of this age have little room in their diets for "empty" calories and these calories can accumulate very easily. Milk was the leading contributor of calories from solid fat and added sugars in FITS 2008 and also in NHANES [42]. The 2015 Dietary Guidelines [10] and the American Academy of Pediatrics [43] recommend that parents and caregivers begin feeding fat-free or low-fat milk at age 2 . A previous analysis of FITS 2008 data showed that about one-quarter to one-third of 2- and 3-year-olds consumed whole milk and 35 to $45 \%$ consumed $2 \%$ milk; the majority of children consumed only unflavored milk [20]. Substantial reductions in calories from solid fat could be achieved by substituting $1 \%$ and skim milks for whole and $2 \%$ milks. Limiting high-fat/high-sugar dessert and snack items, as well as sweetened beverages would help control intakes of calories from both solid fat and added sugars.

The finding that almost half of 2- and 3-year-old children did not consume recommended amounts of dairy may be surprising. A previous analysis of the FITS 2008 data found that the vast majority of children in this age group (more than $85 \%$ ) consumed some type of milk [20]. This, combined with the fact that fluid milk accounted for $70 \%$ of the cup equivalents of dairy foods consumed by children suggests that the reason for the shortfall in consumption of dairy is related to portion size. That is, most children are consuming milk, but not enough of it.

Approximately $40 \%$ of 2-year-olds and $20 \%$ of 3 year-olds had usual intakes of protein foods below recommended levels, however the prevalence of inadequate protein intakes in the U.S. is low [3] and a previous analysis of FITS 2008 data showed that usual protein intakes of children in these age groups exceeded requirements [1]. Two factors contribute to this apparent discrepancy. First, two major sources of protein in children's diets-milk and cheese [21] - are not included in the protein foods group; they are included in the dairy group. Second, estimates of the amounts of protein foods consumed are based on ounce (oz.) equivalents of lean meat, as reported in the 
MPED. Many meat, poultry, and fish items that are popular with children are breaded and/or fried so, ounce for ounce, these items provide fewer lean meat equivalents than plain, lean choices. For example, $100 \mathrm{~g}(\mathrm{~g})$ of baked or broiled chicken breast, without the skin, provides $3.53 \mathrm{oz}$. lean meat equivalents. A comparable portion of chicken nuggets or breaded chicken patty provides only $2.14 \mathrm{oz}$. lean meat equivalents. Similarly, $100 \mathrm{~g}$ of lean roast beef provides $3.53 \mathrm{oz}$. lean meat equivalents, whereas comparable portions of all-beef bologna or all-beef hot dogs provide 2.79 and $2.71 \mathrm{oz}$. lean meat equivalents, respectively [44].

Like all studies that include food grouping systems, findings about the sources of food group intakes are influenced by how specific foods were classified. Some foods that it may have been interesting to analyze separately were grouped together in the analysis for ease in presentation and interpretation or because sample sizes were small (for example, it was not possible to report on green vegetables or legumes separately because of low consumption). In addition, the source data are subject to measurement error associated with any selfreported dietary intake data. Great care was taken in FITS 2008 to minimize measurement error in the collection and coding of the dietary data [24]. Finally, while this analysis could not have been completed without the MPED, the available database has some limitations. Specifically, the version of the database that was used in the analysis is based on foods reported in the 2003-2004 cycle of the National Health and Nutrition Examination Survey (NHANES). Thus, the data may not fully reflect the food group content of foods that were in the marketplace at the time FITS 2008 data were collected.

\section{Conclusions}

Educating parents and primary caregivers about recommended feeding patterns is critical. Given that onethird of children under the age of 5 attend regular child care outside the home [45], child care centers and family day care homes also have an important role to play in developing children's food habits and preferences. Specific, practical, and actionable guidance is needed. Evidence shows that increased availability of [46] and repeated exposure to [31] healthy foods increases their consumption. Young children are often reluctant to try new foods, so parents and caregivers need to be educated about normal neophobic responses to new foods and strategies for promoting acceptance [47]. Child care providers can provide a healthy food environment for children, promote and model recommended dietary patterns, and educate parents about healthy eating habits [48-50].

\section{Additional file}

Additional file 1: Sources of Total Vegetables, Total Grains, Whole Grains, Oils, and Calories from Solid Fat and Added Sugars in Diets of 2- and 3-Year-Old Children. (XLSX 16 kb)

\section{Abbreviations}

FITS: Feeding infants and toddlers study; g: gram; MPED: My pyramid equivalents database; NDS-R: Nutrition data system for research; NHANES: National Health and Nutrition Examination Survey; Oz: ounce/ounce equivalent; SE: Standard error; U.S.: United States of America; USDA: U.S. Department of Agriculture

\section{Acknowledgements}

The authors acknowledge staff at the University of Minnesota's Nutrition Coordinating Center, who collected the 24-h dietary recall data. They also thank Nicholas Beyler of $2 \mathrm{M}$ Research Services (formerly with Mathematica Policy Research) and Kevin Dodd of the National Cancer Institute, who consulted on statistical issues related to estimation of usual food intakes, as well as Rosalie Malsberger and Katherine Niland of Mathematica Policy Research, who helped create data files and assemble and proof tables and figures.

\section{Funding}

The research described in this paper was funded by Nestle Nutrition (Florham Park, NJ, USA) through a competitively awarded contract with Mathematica Policy Research (Princeton, NJ, USA) and its subcontractor, the University of Minnesota (Minneapolis, MN, USA).

\section{Availability of data and materials}

Data supporting the results presented in this paper are not publicly available. The data were used here with permission by coauthors from Mathematica Policy Research, who collected and analyzed the data, and Nestle Nutrition, who funded the research through a competitively awarded contract. Interested parties may contact Kathleen Reidy Kathleen.Reidy@rd.nestle.com for more information about FITS.

\section{Authors' contributions}

MKF conceived of the analysis, drafted the manuscript, and had primary responsibility for final content; EG assisted with data preparation and contributed to the draft manuscript; JC prepared the data and implemented all analyses; $R B, D D, A E$ and $K R$ contributed to the interpretation of results and provided substantive review and input on the manuscript. All authors read and approved the final version of the manuscript.

\section{Competing interests}

The authors declare that they have no competing interests.

Consent for publication

Not applicable.

\section{Ethics approval and consent to participate}

All survey instruments and procedures were approved by Mathematica's independent institutional review board at the time of the study (Public/ Private Ventures in Philadelphia, Pennsylvania). All participants received written information about the study, understood that participation was voluntary, and were assured of the confidentiality of the data.

\section{Author details}

${ }^{1}$ Mathematica Policy Research, 955 Massachusetts Avenue, Cambridge, MA 02138, USA. ${ }^{2}$ Mathematica Policy Research, 600 Alexander Park, Princeton, NJ 08540, USA. ${ }^{3}$ Mathematica Policy Research, 1100 1st Street, N.E., Washington, DC 20002, USA. ${ }^{4}$ Nestle Infant Nutrition, Global R\&D, 12 Vreeland Road, Florham Park, NJ 07932, USA. ${ }^{5}$ Nestlé Research Center, Route du Jorat 57, Vers-chez-les-Blanc, 1000 Lausanne-26, Switzerland.

Received: 14 June 2016 Accepted: 3 November 2016 Published online: 15 November 2016 


\section{References}

1. Butte NF, Fox MK, Briefel RR, Siega-Riz AM, Dwyer JT, Deming DM, Reidy KC. Nutrient intakes of U.S. infants, toddlers, and preschoolers meet or exceed Dietary Reference Intakes. J Am Diet Assoc. 2010;110:S27-37.

2. Condon E, Drilea S, Lichtenstein C, Mabli J, Madden E, Niland K. Diet Quality of American Young Children by WIC Participation Status: Data from the National Health and Nutrition Examination Survey, 2005-2008. Prepared by Walter R. McDonald \& Associates, Inc. and Mathematica Policy Research. Alexandria: U.S. Department of Agriculture; 2015.

3. Moshfegh A, Goldman J, Cleveland L. What We Eat in America, NHANES 2001-2002: Usual Nutrient Intakes From Food Compared to Dietary Reference Intakes. Washington: U.S. Department of Agriculture, Agricultural Research Service; 2005.

4. Devaney B, Zeigler P, Pac S, Karwe V, Barr SI. Nutrient intakes of infants and toddlers. J Am Diet Assoc. 2004;104:S14-21.

5. Ogden $\mathrm{CL}$, Carroll MD, Kit BK, Flegal KM. Prevalence of childhood and adult obesity, 2011-2012. JAMA. 2014:311:806-14.

6. Wen X, Gillman MW, Rifas-Shiman SL, Sherry B, Kleinman K, Taveras EM. Decreasing prevalence of obesity among young children in Massachusetts from 2004 to 2008. Pediatrics. 2012;129:823-31.

7. Berger M, Konty K, Day S, Silver LD, Nonas C, Kerker BD, Greene C, Farley T. Obesity in K-8 students-New York City, 2006-07 to 2010-11 school years. MMWR Morb Mortal Wkly Rep. 2011;60:1673-8.

8. May AL, Freedman D, Sherry B, Blanck HM. Centers for Disease Control and Prevention. Obesity: 1999-2010. MMWR Morb Mortal Wkly Rep. Supplements. 2013;62:120-8.

9. Ogden $\mathrm{CL}$, Carroll MD, Kit BK, Flegal KM. Prevalence of obesity and trends in body mass index among US children and adolescents, 1999-2010. JAMA. 2012;307(5):483-90.

10. U.S. Department of Health and Human Services and U.S. Department of Agriculture. 2015 - 2020 Dietary Guidelines for Americans. 8th Edition. December 2015. http:/health.gov/dietaryguidelines/2015/guidelines/. Accessed 14 Apr 2016.

11. Krebs-Smith SM, Guenther PM, Subar AF, Kirkpatrick SI, Dodd KW. Americans do not meet federal dietary recommendations. J Nutr. 2010;140:1832-8.

12. Guenther PM, Dodd KW, Reedy J, Krebs-Smith SM. Most Americans eat much less than recommended amounts of fruits and vegetables. J Am Diet Assoc. 2006;106:1371-9.

13. Harnack L, Walters S-A H, Jacobs Jr DR. Dietary intake and food sources of whole grains among US children and adolescents: Data from the 19941996 Continuing Survey of Food Intakes by Individuals. J Am Diet Assoc. 2003;103:1015-9.

14. Birch LL. Development of food acceptance patterns in the first year of life Proc Nutr Soc. 1998:57:617-24.

15. Birch LL, Savage JS, Ventura A. Influences on the development of children's eating behaviors: From infancy to adolescence. Can J Diet Pract Res. 2007;68:S1-56

16. Brug J, Tak NI, te Velde SJ, Bere E, de Bourdeaudhuij I. Taste preferences, liking and other factors related to fruit and vegetable intakes among schoolchildren: Results from observational studies. Br J Nutr. 2008:99:S7-14.

17. Skinner JD, Carruth BR, Bounds W, Ziegler PJ. Children's food preferences: a longitudinal analysis. J Am Diet Assoc. 2002;102:1638-47.

18. Raiten DJ, Raghavan R, Porter A, Obbagy JE, Spahn JM. Executive summary: evaluating the evidence base to support the inclusion of infants and children from birth to 24 mo of age in the Dietary Guidelines for Americans - "The B-24 Project.". Am J Clin Nutr. 2014;99:663S-91.

19. Fox MK, Pac S, Devaney B, Jankowski L. Feeding infants and toddlers study: what foods are infants and toddlers eating? J Am Diet Assoc. 2004;104:S22-30.

20. Fox MK, Condon E, Briefel RR, Reidy KC, Deming DM. Food consumption patterns of young preschoolers: Are they starting off on the right path? J Am Diet Assoc. 2010;110:S52-9.

21. Fox MK, Reidy K, Novak T, Zeigler P. Sources of energy and nutrients in the diets of infants and toddlers. J Am Diet Assoc. 2006:106:S28-42.

22. Siega-Riz AM, Deming DM, Reidy KC, Fox MK, Condon E, Briefel RR. Food consumption patterns of infants and toddlers: where are we now? J Am Diet Assoc. 2010;110:S38-51.

23. Dwyer JT, Butte NF, Deming DM, Siege-Riz AM, Reidy KC. Feeding infants and toddlers study 2008: progress, continuing concerns, and implications. J Am Diet Assoc. 2010;110:S60-7.

24. Briefel RR, Kalb LM, Condon E, Deming DM, Clusen NA, Fox MK, Harnack L, Gemmill E, Stevens M, Reidy KC. The feeding infants and toddlers study 2008: study design and methods. J Am Diet Assoc. 2010;110:S16-26.
25. Nestlé Feeding Infants and Toddlers Study (FITS). http://medical.gerber.com/ NutritionEducation/FITSStudy.aspx. Accessed 25 Apr 2016.

26. Bowman SA, Friday JE, Moshfegh AJ. MyPyramid equivalents database, 2.0 for USDA survey foods, 2003-2004. Washington: U.S. Department of Agriculture, Agricultural Research Service; 2008.

27. Usual Dietary Intakes: SAS Macros for the NCI Method. http://riskfactor. cancer.gov/diet/usualintakes/macros.html. Accessed 12 Mar 2012.

28. Butte NF, Wong WW, Wilson TA, Adolph AL, Puyau MR, Zakeri IF. Revision of dietary reference intakes for energy in preschool-age children. Am J Clin Nutr. 2014;100:161-7.

29. Subar AF, Krebs-Smith SM, Cook A, Kahle LL. Dietary sources of nutrients among US children, 1989-1991. Pediatrics. 1998;102:913-23.

30. Bachman JL, Reedy J, Subar AF, Krebs-Smith SM. Sources of food group intakes among the U.S. population, 2001-2002. J Am Diet Assoc. 2008:108:804-14.

31. Birch LL, Doub AE. Learning to eat: birth to age 2 y. Am J Clin Nutr. 2014;99:723S-8

32. Dovey TM, Staples PA, Gibson EL, Halford JC. Food neophobia and 'picky/ fussy' eating in children: a review. Appetite. 2008:50:181-93.

33. Perry RA, Mallan KM, Koo J, Mauch CE, Daniels LA, Magarey AM. Food neophobia and its association with diet quality and weight in children aged 24 months: a cross sectional study. Int J Behav Nutr Phys Act. 2015;12:13. doi:10.1186/s12966-015-0184-6.

34. Mennella JA. The sweet taste of childhood. In: Basaum Al, Kaneko A, Shepherd GM, Westheimer G, editors. The senses: a comprehensive reference. San Diego: Academic; 2008. p. 183-8.

35. Wardle J, Herrera M-L, Cooke L, Gibson EL. Modifying children's food preferences: the effects of exposure and reward on acceptance of an unfamiliar vegetable. Eur J Clin Nutr. 2003;57:341-8.

36. Anzman-Frasca S, Savage JS, Marini ME, Fisher JO, Birch LL. Repeated exposure and associative conditioning promote preschool children's liking of vegetables. Appetite. 2012;58:543-53.

37. Addessi E, Galloway AT, Visalberghi E, Birch LL. Specific social influences on the acceptance of novel foods in 2-5-year-old children. Appetite. 2005;45:264-71.

38. Hendy HM. Effectiveness of trained peer models to encourage food acceptance in preschool children. Appetite. 2002;39:217-25.

39. Branum AM, Rossen LM. The contribution of mixed dishes to vegetable intake among U.S. children and adolescents. Public Health Nutr. 2014:17(9):2053-60.

40. American Academy of Pediatrics, Committee on Injury, Violence, and Poison Prevention. Prevention of choking among children. Pediatrics. 2010;125(3):601-7.

41. Savage JS, Peterson J, Marini M, Bordi PL, Birch LL. The addition of a plain or herb-flavored reduced-fat dip is associated with improved preschoolers' intake of vegetables. J Acad Nutr Diet. 2013;113:1090-5.

42. Grimes CA, Szymlek-Gay EA, Campbell KJ, Nicklas TA. Food sources of total energy and nutrients among U.S. infants and toddlers: National Health and Nutrition Examination Survey 2005-2012. Nutrients. 2015;7:6797-836. doi:10.2290/nu7085310.

43. Daniels SR, Greer FR, and the Committee on Nutrition. Lipid screening and cardiovascular health in childhood. Pediatrics. 2008;122:198-208.

44. Fox MK, Clark M, Condon E, Wilson A. Diet quality of school-age children in the U.S. and Association with Participation in the School Meal Programs. Washington: Department of Agriculture, Economic Research Service; 2010.

45. Laughlin L. Who's Minding the Kids? Child Care Arrangements: Spring 2011. Current Population Reports, P70-135. Washington, DC: U.S. Census Bureau, Available at http://www.census.gov/prod/2013pubs/p70-135.pdf.

46. Hearn MD, Baranowski T, Baranowski J, Doyle C, Smith M, Lin LS, Resnicow K. Environmental influences on dietary behavior among children: availability and accessibility of fruits and vegetables enable consumption. J Health Ed. 1998:29:26-32.

47. Fisher JO, Wright G, Herman AN, Malhotra K, Serrano EL, Foster GD, Whitaker RC. "Snacks are not food". Low-income, urban mothers' perceptions of feeding snacks to their preschool-aged children. Appetite. 2015:84:61-7.

48. American Academy of Pediatrics, American Public Health Association, and National Resource Center for Health and Safety in Child Care and Early Education. Preventing Childhood Obesity in Early Care and Education: Selected Standards from Caring for Our Children: National Health and Safety Performance Standards; Guidelines for Early Care and Education Programs, 3rd 
Edition; 2012. http://nrckids.org/CFOC3/PDFVersion/preventing_obesity.pdf. Accessed 10 July 2013.

49. Institute of Medicine. Early childhood obesity prevention policies: goals, recommendations, and potential actions. Washington: National Academies Press; 2011.

50. Neelon SEB, Briley ME. Position of the American dietetic association: benchmarks for nutrition in child care. J Am Diet Assoc. 2011;111:607-15.

Submit your next manuscript to BioMed Central and we will help you at every step:

- We accept pre-submission inquiries

- Our selector tool helps you to find the most relevant journal

- We provide round the clock customer support

- Convenient online submission

- Thorough peer review

- Inclusion in PubMed and all major indexing services

- Maximum visibility for your research

Submit your manuscript at www.biomedcentral.com/submit
Biomed Central 